\title{
High-Dose Cytarabine Regimen
}

National Cancer Institute

\section{Source}

National Cancer Institute. High-Dose Cytarabine Regimen. NCl Thesaurus. Code C160046.

A chemotherapy regimen consisting of high-dose cytarabine that may be used in the treatment of acute myeloid leukemia (AML) and primary central nervous system (CNS) lymphoma. 